\title{
Nota científica / Short communication Horto do Colégio dos Jesuítas: notícias do primeiro jardim botânico no Rio de Janeiro
}

\author{
Garden of the Jesuits' College: news about the first botanical garden in Rio de Janeiro
}

\author{
Marcos Gonzalez ${ }^{1,2,3}$, Ariane Luna Peixoto ${ }^{1}$ \& Begonha Bediaga ${ }^{1}$
}

\begin{abstract}
Resumo
Apresenta-se o Horto do Colégio dos Jesuítas, na encosta do Morro do Castelo, como um local de experimentação de culturas de plantas com potencial retorno econômico, em contexto que antecede a criação do Jardim Botânico do Rio de Janeiro (1808).

Palavras-chave: Botânica; aclimatação de plantas; história das instituições; história das ciências.

Abstract

We present the Garden of the Jesuits' College, at the hillside of the Morro do Castelo, as a place of experimentation of plant cultivations with potential economic return, in a context that precedes the creation of the Rio de Janeiro Botanical Garden (1808).
\end{abstract}

Key words: Botany; acclimatization of plants; history of institutions; history of the sciences.

O Real Jardim Botânico da Ajuda, fundado em 1768 em Lisboa, constituía, com o Museu de História Natural, a Casa do Risco e o Laboratório Químico, o "complexo científico e museológico" de História Natural de Ajuda. A sua missão era reunir e sistematizar plantas, animais, madeiras, minerais e outros exemplares da natureza enviados pelas colônias portuguesas, sobretudo da América e África (Brigola 2016). O Complexo foi concebido pelo naturalista italiano Domingos Vandelli, seu diretor até 1772 , ocasião em que foi nomeado lente de História Natural e Química na Universidade de Coimbra, onde também inaugurou e dirigiu o jardim botânico da instituição. Foi professor de muitos naturalistas brasileiros que aí se formaram nas últimas décadas do século XVIII (Domingues 2001).

A notoriedade de Vandelli em Portugal decorria principalmente da numerosa correspondência que ele mantinha com diversas academias de ciências e jardins botânicos, e com os principais homens das ciências na época, a exemplo de Lineu e Jussieu. Seu pensamento incorporava o conhecimento científico que despontava na Europa, influenciado pela "doutrina econômica fisiocrática, defensora do progresso a partir da produção primária" (Pádua 2002, p.14). Essa reflexão pode ser constatada na sua publicação Memória sobre a utilidade dos Jardins Botânicos, de 1770. A obra, reeditada em 1788, atribuía parte do desenvolvimento de países europeus ao estabelecimento de jardins botânicos em seus territórios. Mostrava, também, que as experiências focadas nos estudos da vegetação das colônias resultavam em grandes proveitos econômicos para as metrópoles. Ainda que de forma discreta, o texto expõe o descompasso de Portugal perante as demais monarquias e sustenta, com veemência, a tese da necessidade de investimento em história natural:

Quão grande seja a utilidade de um jardim botânico (além do gosto de ver juntas as plantas de todas as partes do mundo, e do proveito que delas recebem a medicina, as artes, o comércio etc.) para a agricultura, só o ignora aquele que não sabe quantas plantas de regiões remotas por meio dos jardins são hoje comuns e ordinárias na Europa, e cujo número se vai cada dia aumentando; de que

\footnotetext{
Instituto de Pesquisas Jardim Botânico do Rio de Janeiro, R. Pacheco Leão 915, Jardim Botânico, 22460-030, Rio de Janeiro, RJ, Brasil.

${ }^{2}$ ORCID: < https://orcid.org/0000-0002-2004-353X>

${ }^{3}$ Autor para correspondência: gonzalez@jbrj.gov.br
} 
é prova evidente França, Suécia e Alemanha. Porquanto, com o conhecimento botânico adquirido nos mais célebres jardins, têm os ingleses e franceses examinado e reconhecido a maior parte das plantas que nascem nas suas conquistas da América, e têm tirado imensa utilidade, e cada vez poderão tirar mais lucro (Vandelli 1770, p.5-8).

A narrativa, com nítido objetivo de convencimento, elenca 69 jardins botânicos e cita sete monarcas que haviam patrocinado expedições de naturalistas pelo mundo para "descobrir novas plantas" (Id. Ibid. p.6-7). Sustenta que o reino português devia se aproximar dos sistemas coloniais francês e inglês e assim, conforme assinalado por Kury (2004, p.111), investir nos recursos naturais do Brasil e colônias da África como possibilidades de recobrar o antigo poderio colonial.

Outro personagem fundamental para compreender os jardins botânicos na conjuntura do iluminismo luso-brasileiro foi Rodrigo de Souza Coutinho. Ao ser nomeado Ministro de Estado dos Negócios da Marinha, e Domínios Ultramarinos, em 1796, Coutinho agiria diretamente na política da Corte e das colônias, tendo ao seu lado brasileiros egressos de Coimbra e discípulos formados por Vandelli, que passaram a contar com sua proteção e agir sob sua coordenação (Pereira 2014).

Coutinho não era um homem de ciências como Vandelli. Contudo, exerceu o poder incentivando, de forma eficaz, o conhecimento prático acerca dos recursos naturais das colônias como relevante solução econômica para o progresso do reino. Documentos da época mostram que uma das prioridades do ministro era estabelecer uma rede de jardins botânicos envolvendo diversas províncias do Brasil, inserida na política fomentista da segunda metade do século XVIII. Segundo Carolino (2014), "o programa científico de Rodrigo de Souza Coutinho era norteado por uma linha de força caracteristicamente iluminista" que, através de instruções administrativas, almejava implantar estabelecimentos de caráter técnico-científico, com vistas a equiparação do império luso às demais potências europeias.

As pesquisas de Sanjad $(2001,2006)$ sobre jardins botânicos mostram que a administração de Souza Coutinho foi além do fomento a iniciativas que dependessem de esforços esparsos e habilidades individuais de vice-reis ou lavradores. Dentre as diversas ações do ministro, o autor destaca a criação do Jardim Botânico São
José, em Belém do Pará, em 1798, o primeiro fora da metrópole portuguesa, que deveria servir de modelo para a criação das demais instituições semelhantes em outras capitanias. A partir de então foram implementadas políticas de incentivo ao intercâmbio de plantas e conhecimentos entre as colônias, constituindo o que Sanjad (2001) chama de "rede luso-brasileira de jardins botânicos".

A presente nota científica lança luz sobre os esforços do governo português em estabelecer um polo dessa rede na capital da colônia, projeto que vinha sendo acalentado havia muito anos antes de sua efetiva concretização na lagoa Rodrigo de Freitas.

De fato, dois membros de uma missão diplomática inglesa, que permaneceu pouco mais de duas semanas no Rio de Janeiro em 1792', mencionam a existência de um "jardim pertencente à coroa" que ficava "perto [do centro] da cidade, à beira-mar". Após visitarem o Passeio Público², George Staunton (1737-1801) e John Barrow (1764-1848) conheceram este jardim que, conforme Staunton, era "de outro tipo", porque fora destinado "originalmente, ao progresso da botânica", do qual restava então apenas uma "manufatura de cochonilha" (Staunton 1797, p.164). Barrow nos oferece informações mais detalhadas sobre este lugar hoje desaparecido:

Existe outro jardim pertencente à coroa, que é principalmente destinado ao cultivo daquelas espécies de cactos em que o inseto da cochonilha se alimenta e à recepção de plantas nativas curiosas ou úteis; mas o encontramos muito negligenciado, e a coleção é muito limitada, contendo apenas poucas plantas nativas que ainda não foram cultivadas nas estufas da Inglaterra (Barrow 1806, p.83-84).

Esse jardim ficava em uma "cerca" ou "chácara" contígua ao antigo Colégio dos Jesuítas, localizado no Morro do Castelo, e pode ser

\footnotetext{
'O objetivo da missão, chefiada pelo diplomata George Macartney (17371806), era negociar um acordo que garantisse os interesses comerciais ingleses na região de Pequim, na China.

${ }^{2}$ O Passeio Público (v. fig. 1) foi criado na década de 1780 por ordem do vice-rei Luís de Vasconcelos, que encarregou o escultor e arquiteto Valentim da Fonseca e Silva ("Mestre Valentim, ca.1745-1813) de traçar o ambiente, um aterro onde antes havia áreas alagadas e charnecas. $\mathrm{O}$ objetivo, conforme Segawa (1996, p.81), era "alinhar o desenvolvimento da cidade em direção sul [...], estabelecendo a comunicação para os lados dos futuros bairros de Flamengo e Botafogo, bem como de implantar signos de urbanização, mediante o alinhamento de novas ruas".
} 

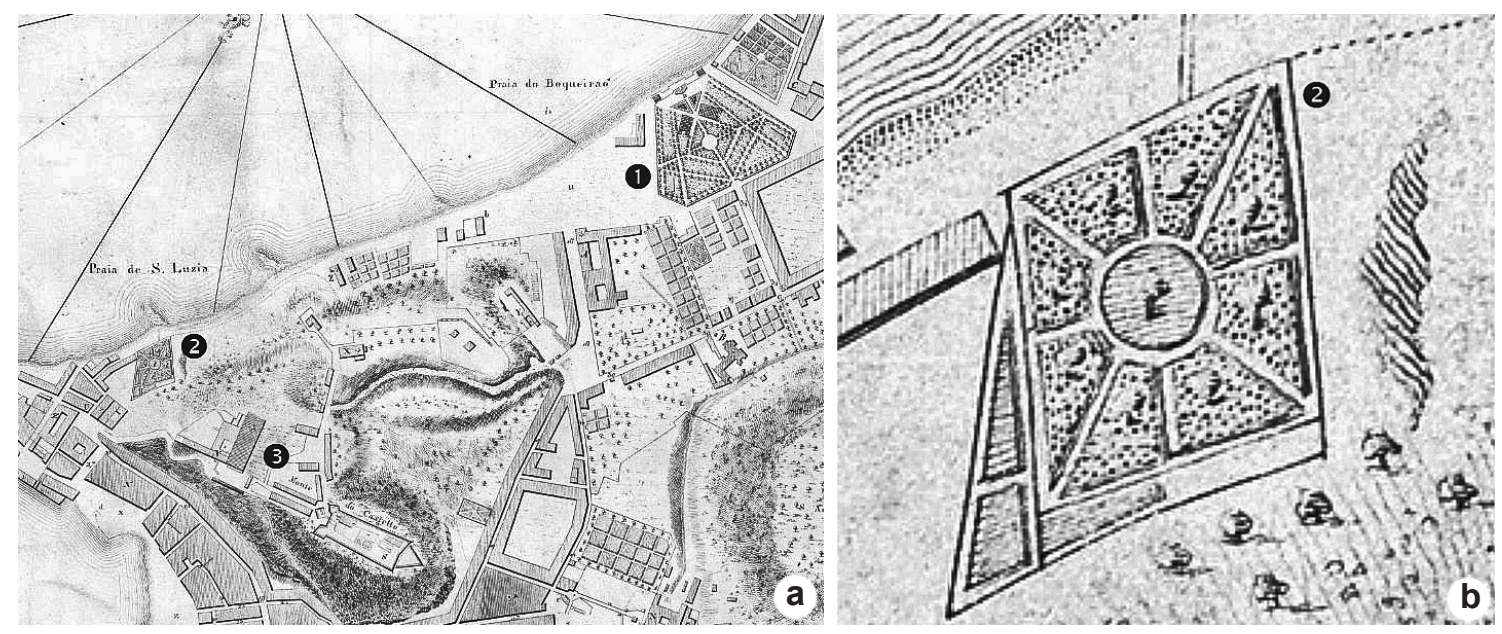

Figura 1 - Planta da cidade de São Sebastião do Rio de Janeiro (Souto 1812). No detalhe (a), destaque para (1) o Passeio Público; (2) o Horto do Colégio; (3) Hospital Militar, edificação no Morro do Castelo que até 1760 abrigara o Colégio dos Jesuítas. Em (b), o Horto do Colégio, onde se pode vislumbrar seu paisagismo. Figure 1 - Plan of the city of São Sebastião do Rio de Janeiro (Souto, 1812). In detail (a), highlight to (1) the Passeio Público; (2) the Garden of the Jesuits' College; (3) Military Hospital, building on Morro do Castelo that until 1760 had housed the Jesuits' College. In (b), the Garden of the Jesuits' College, where we can observe its landscaping.

observado na Planta da cidade de S. Sebastião do Rio de Janeiro, cartografada por Paulo dos Santos Ferreira Souto em 1812 (Fig. 1).

Após a expulsão da Ordem dos Jesuítas em 1759, o Colégio, confiscado pela Coroa, teve diferente usos, até ali se instalar o Hospital Real Militar, cerca de dez anos depois (Silva 1997, p.980-981). O horto anexo permaneceu ativo para benefício do hospital. Frei Custódio de Campos e Oliveira, nomeado cirurgião-mór dos Reais Exércitos e Armada de Portugal, consultando o livro em que os vice-reis do Brasil registraram seus mandados, descobriu que Luís de Almeida Portugal Soares de Alarcão Eça e Melo Silva e Mascarenhas (1729-1790), o marquês de Lavradio³, vice-rei do Brasil e governador do Rio de Janeiro entre 1769-1778, implantou no espaço:

uma horta e jardim botânico para uso dos doentes e para provimento da botica, [que] servia para passearem os convalescentes e para efetivamente fazerem exercício os enfermos precisados dele, e tinha um caminho destinado para serem conduzidos para banhos de mar e sempre para, entre muros, todos aqueles a quem os médicos e cirurgiões julgaram precisados dos

${ }^{3}$ Doravante "marquês de Lavradio". ditos banhos. Tem água bastante para regar as plantações, tem árvores frutíferas e tem horta, tudo conducente para bem do enfermo (Oliveira 1808).

Essa "horta e jardim botânico" foi aproveitada em 1772 pela Academia Científica do Rio de Janeiro, fundada sob o amparo do mesmo vice-rei. A instituição, de curta trajetória, foi identificada por Marques (2005) como uma "escola na qual formavam-se homens de ciências". A iniciativa fomentava a observação da natureza, a realização de experimentos, o debate de descobertas, um lugar para troca de informações e reflexões de políticas que pudessem subsidiar o Reino no que se refere à melhor exploração econômica da colônia. Podemos distinguir nesse período os irmãos portugueses José Henriques Ferreira e Manoel Joaquim Henriques de Paiva, responsáveis pelas primeiras experiências com a cochonilha fora dos domínios espanhóis ${ }^{4}$.

José Henriques, filósofo e médico do marquês de Lavradio, mantinha correspondência com a Academia Real das Ciências da Suécia e era sócio

\footnotetext{
${ }^{4}$ Conforme Papavero \& Claps (2014, p.18), os insetos chamados de cochonilha (entre outros nomes vulgares) são Dactylopiidae (Hemiptera: Coccoidea), uma família monogenérica, endêmica do Novo Mundo, principalmente dos desertos ou regiões semiáridas dos Estados Unidos, México e América do Sul. São conhecidos comumente como "cochonilhas do carmim" e estão intimamente relacionados com as Cactaceae, já que vivem exclusivamente sobre estes vegetais.
} 
da Academia Real de Medicina de Madri. Seu interesse pelas questões científicas e econômicas em torno da fabricação do corante vermelho para a indústria têxtil pode ser aferido na História do Descobrimento da Cochonilha no Brasil (Ferreira \& Paiva 1772-1773). O texto, escrito em 1772, no ano seguinte foi entregue, comentado, à Academia do Rio de Janeiro por seu irmão mais novo, Manoel Joaquim, químico, farmacêutico e médico.

Quarenta anos depois, o referido trabalho seria citado nos debates acerca da controvérsia científica sobre a produção da cochonilha, que envolveu Manoel Joaquim de Paiva e outro médico, Jacinto José da Silva Quintão (1813), publicada em $O$ Patriota ${ }^{5}$. Na réplica, Paiva $(1814$, p.11) se refere ao Horto do Colégio como "Jardim Botânico do Rio de Janeiro".

O projeto de um jardim botânico estava previsto nos estatutos da Academia Científica (apud Silva 2013, p.49): “Terá a Academia um Horto Botânico para nele se tratarem e recolherem todas as plantas notáveis, e terá cada acadêmico obrigação de o ir ver para observar a diferença e crescimento delas". Escolheram instalá-lo no mesmo lugar onde havia sido o antigo Horto, como comenta Manuel Joaquim em nota ao texto do irmão, "na cerca do colégio que foi dos Jesuítas, e que hoje serve de Hospital Militar: esta cerca se achava inculta, mas à custa do $\mathrm{Ex}^{\mathrm{mo}}$. vice-rei [marquês de Lavradio] e pelo cuidado do coletor Antonio José Castrioto, esta hoje é agradável e útil jardim aonde se cultivam muitas plantas" (Ferreira \& Paiva 1772-1773).

O próprio marquês de Lavradio, Luís de Almeida Silva e Mascarenhas (1842 [1789], p.474), confirma no relatório sobre seu governo remetido ao seu sucessor, Luís de Vasconcellos e Souza, em 1779:

Conservei do mesmo arbusto [cactos para produção da cochonilha] bastantes pés em um horto botânico, que aqui estabeleci, e de que se acha encarregado, e com a inspeção dele Joaquim José Henrique de Paiva.

Pode-se inferir, portanto, que os diversos cactos que os ingleses Staunton e Barrow observaram no jardim do Morro do Castelo fossem um legado dos tempos dos irmãos Paiva, vinte anos antes.

\footnotetext{
${ }^{5}$ Periódico de vida curta, que publicou 18 fascículos entre 1813 e 1814 , dando relevância às produções científicas de brasileiros (Kury 2007).
}

O Horto do Colégio (ou da Academia) já fazia parte da memória da cidade quando, em dezembro de 1795, o vice-rei José Luís de Castro, conde de Rezende, recebeu uma carta do médico Manoel Joaquim de Souza Ferraz propondo a criação, "com mui tênue despesa", de um "Jardim Médico Botânico" no Rio de Janeiro (Ferraz 1795). Ocorreu ao vice-rei aquele mesmo local, como revela a carta que enviou à Metrópole recomendando o projeto:

[...] para que em uma horta chamada do Colégio, que é de S.M. e está contigua ao Hospital Militar se cuide na plantação de muitas ervas para uso da Botica do mesmo hospital, as quais tem-se descoberto serem conhecidamente profícuas, e ao mesmo tempo concorrerem para a diminuição da despesa que a Fazenda Real é obrigada a fazer na compra de outras ervas, e raízes estrangeiras (Castro 1795).

Conforme explicitado anteriormente, desde a nomeação de Rodrigo de Souza Coutinho como ministro do Ultramar, em 1796, os jardins botânicos ganharam maior incentivo. Isso pode ser constatado na Carta Régia de 1798, em que Souza Coutinho demandava aos governadores de São Paulo, Bahia, Minas Gerais, Maranhão, Mato Grosso, Goiás, Rio Grande de São Pedro (atual Rio Grande do Sul) e Rio de Janeiro, que estabelecessem nessas capitanias,

com a menos despesa que for possível, um jardim botânico semelhante ao do Pará, em que se cultivem todas as plantas assim indígenas, como exóticas, e em que particularmente se cuide em propagar de semente as árvores que dão madeira de construção para depois se semearem nas matas reais (D. João VI 1798).

Em relação à cidade do Rio de Janeiro, as ordens foram reafirmadas em ofício posterior, e indicava que fosse executado o cultivo do cânhamo ${ }^{6}$ com a justificativa baseada na localização geográfica e clima. Ainda em 1798, em discurso proferido na abertura da Sociedade Real Marítima, Souza Coutinho revela suas esperanças na produção da cordoaria, tanto militar quanto a mercante, obtida da expansão do cultivo dessa espécie no sul da América, onde sua cultura já fora testada outrora:

\footnotetext{
${ }^{6}$ Trata-se da Cannabis sativa, espécie descrita por Carlos Lineu em 1753. Integra a família botânica Cannabaceae, que engloba 10 gêneros e cerca de 110 espécies, segundo circunscrição do APG IV (2016). O termo 'linhaça (de linho cânhamo)', mencionado ao longo do artigo, referia-se na época às sementes dessa espécie (cf. Vieyra 1813, verbete hemp).
} 
A Real Fabrica da Cordoaria e Lonas [de Lisboa] aumentada por S.A.R. temse elevado ao ponto que em poucos anos nada destas manufaturas virá de fora, particularmente logo que o linho e cânhamo do Rio Grande [do Sul], de Paraguai, e dos Campos da Curitiba vier na abundância que justamente se espera depois que se houverem executado as providencias que S.A.R. tem mandado dar (Coutinho 2008 [1798], p.111). Segundo Wehling (1977), a cultura do cânhamo era de particular interesse de Souza Coutinho na busca do fortalecimento do Erário. Com efeito, a produção se manteve rentável por algum tempo, reduzindo os déficits da balança comercial e animando o discurso do ministro:

Quanto não seriam dignas para exemplo dos outros soberanos de serem citadas com o maior elogio as providências, dadas por Sua Alteza Real, para animar a cultura do linho cânhamo em muitos distritos do Reino? Já fornecendo as sementes; já segurando ao lavrador a boa venda da sua colheita; já fazendo-o instruir nas melhores práticas d'esta cultura, únicos meios com que um soberano cheio de luzes, e pai de seus povos pôde procurar naturalizar entre eles uma cultura ou nova, ou quase abandonada; e de que poderá seguir-se-lhe grandes (Coutinho 2008 [1800], p.120).

No Rio de Janeiro, o vice-rei José Luís de Castro afirmava estar em condições de atender prontamente à demanda do ministro em relação ao cânhamo e outras espécies úteis, pois não deixara de investir no Horto do Colégio. A despeito de experiências fracassadas, o vice-rei se convenceu de que, com "homens mais cuidadosos" e "sementes novas, bem escolhidas, e já produzidas neste mesmo clima", seria possível em pouco tempo "generalizar esta cultura e tirarem-se todas as vantagens que ela promete". Com a "especialidade pelo conhecimento ocular que tirei da experiência feita no horto botânico estabelecido nesta cidade na Horta que foi dos Jesuítas", Castro conseguira colher pés de 13 palmos de altura, além de uma boa porção de semente, que pretendia mandar fazer "em tempo competente diversas plantações" (Castro 1799).

Além do cânhamo, o governo estava empenhado também em ampliar ou iniciar outras culturas. Em carta ao futuro vice-rei Fernando José de Portugal e Castro, o príncipe regente d. João elenca as prioridades já apresentadas a seu antecessor em 1797. Dentre as muitas recomendações de cunhos diversos (religioso, social, justiça, etc.), reafirma especial preocupação em desenvolver as culturas no Rio de Janeiro que caracterizavam, na sua perspectiva, a função econômica dos jardins botânicos:

[...] procureis aperfeiçoar e ampliar as culturas já existentes nessa Capitania, e animar as novas que tinha mandado recomendar ao vosso predecessor [José Luís de Castro], quais sejam a da pimenta, canela, árvore do pão, cravo da Índia e das outras especiarias, a do linho cânhamo e o cacto da cochonilha, para cujo efeito muito pode contribuir a ereção de um econômico jardim botânico, já principiado pelo dito vosso predecessor à imitação do que Mandei estabelecer na Capitania do Pará, podendo no mesmo jardim botânico praticarem-se primeiro em pequeno as culturas daquelas plantas que hajam, depois de estender-se a toda Capitania (D. João VI 1800).

Cabe realçar na carta a menção ao Horto do Colégio, "principiado pelo dito vosso predecessor", como um jardim botânico à semelhança daquele do Pará. Seu potencial econômico fora reconhecido também por Rodrigo de Souza Coutinho que, em carta de 1801 (Fig. 2), elogia o cânhamo ali produzido:

Como tenho feito maior impressão no ânimo dos lavradores desta Capitania os efetivos lucros que percebem da cultura dos gêneros próprios do país, do que as esperanças, que lhes poderia prometer a plantação de linho cânhamo, julgo que só por este motivo não se tem resolvido a tratar seriamente deste objeto, e não porque se tenha conhecido impossibilidade de produzir neste clima; como se faz evidente com essa porção de linhaça que recebeu Manoel de Souza, mestre da nau Princesa da Beira, a qual foi beneficiada no Horto Botânico do Colégio (Coutinho 1801).

Entre 1801 e 1806, o desprestígio do anglófilo Rodrigo de Souza Coutinho frente à ascensão do grupo político favorável à aliança com Napoleão parece ter influenciado na produção de linho, que praticamente se extinguiu, "ficando reduzida à feitoria oficial do Rio Grande São Pedro [do Sul] e às tentativas esparsas de particulares" (Wehling 1977, p.171-172). No Rio de Janeiro, o desinteresse se mostra evidente com o arrendamento do Horto do Colégio para Antonio Feliciano Serpa, oficial da Junta da Fazenda, em torno de 1804. 


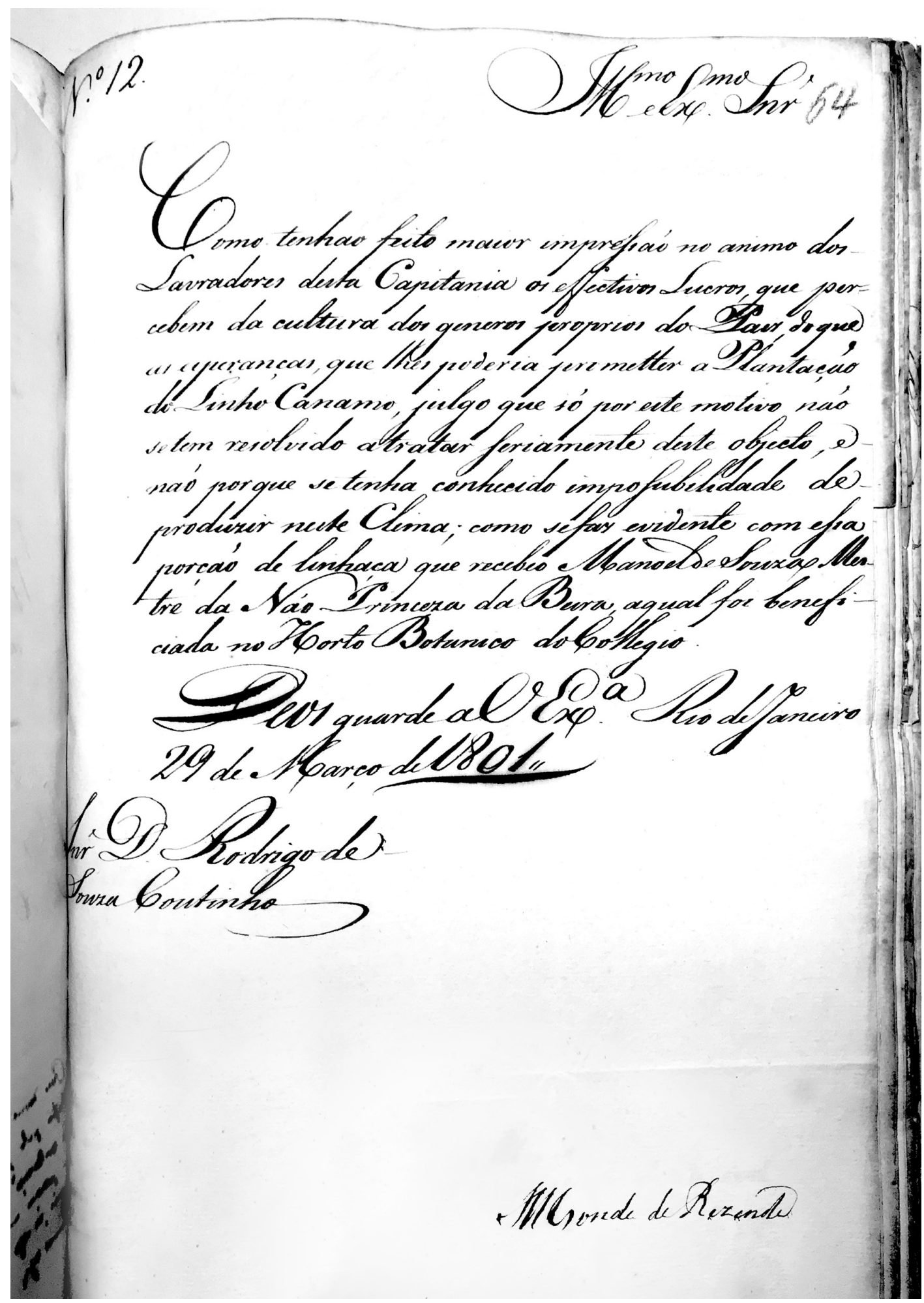

Figura 2 - Carta de Rodrigo de Souza Coutinho ao vice-rei do Brasil, conde de Rezende, com elogios o linho cânhamo produzido no Horto do Colégio dos Jesuítas (Coutinho 1801).

Figure 2 - Letter from Rodrigo de Souza Coutinho to the Viceroy of Brazil, count of Rezende, with praise for the flax hemp produced in the Garden of the Jesuits' College (Coutinho 1801). 
A partir da transferência da corte portuguesa para o Brasil em 1808, o Hospital Real Militar, instalado no antigo Colégio dos Jesuítas, recebe maior atenção com a implantação da Escola Anatômica, Cirúrgica e Médica por iniciativa do pernambucano José Correia Picanço, barão de Goiana, médico da Real Câmara. Seu primeiro diretor, o já citado frei Custódio de Campos e Oliveira, cirurgião-mór dos Reais Exércitos e Armada de Portugal, foi incumbido de reformular a administração do hospital, tendo se empenhado na melhoria de suas instalações, nomeado novos cirurgiões e auxiliares, substituído funcionários pouco qualificados e disciplinado a hierarquia entre médicos e cirurgiões (Silva 1997, p.983). Interessava-lhe, ademais, que o horto botânico contíguo fosse incorporado para uso do referido hospital e, assim, frei Custódio sugeriu que o arrendamento a Antonio Feliciano Serpa fosse encerrado, uma vez que a "chácara em que falei à V.Exa., é, e sempre foi, propriedade pertencente ao hospital" (Oliveira 1808).

As alegações do cirurgião-mór parecem ter sido convincentes, visto que, ao receber sua representação, Rodrigo de Souza Coutinho solicitara ao então presidente do Real Erário, Fernando José de Portugal e Castro, que cancelasse, na Junta da Fazenda, o arrendamento do antigo Horto do Colégio em favor do Hospital:

Passo às mãos de V.Exa. a proposta inclusa do cirurgião-mór dos Exércitos, com a qual S.A.R. se conforma, vista a utilidade, que pode resultar ao hospital, de não se arrendar a sua chácara, podendo se estabelecer nela um jardim botânico, além de que os símplices vegetais e os de horta poderão ser muito úteis ao mesmo hospital. Por todas essas razões, estou persuadido de que será indispensável que V.Exa. escreva logo à Junta da Fazenda, a fim de que fizesse cessar o arrendamento da referida chácara, logo que seja possível e justo (Coutinho 1808a).

Diante deste fato novo, urgia encontrar um outro lugar para um jardim botânico que atendesse aos interesses do príncipe.

O lugar escolhido seria a Lagoa Rodrigo de Freitas, mais especificamente as terras ocupadas desde o século XVI por engenhos de açúcar (Mello Moraes 1879, p.139). A documentação que ali instituiu a Fábrica de Pólvora, produzida no primeiro semestre de 1808 , não explicita nenhuma intenção de também abrigar um jardim botânico. De fato, embora a tradição tenha conservado o
13 de junho de 1808 como data de fundação do Jardim Botânico do Rio de Janeiro, os três decretos publicados nesta data se referem à incorporação aos próprios nacionais das terras do engenho onde a fábrica (fundada em 13 de maio), e também o Jardim Botânico, funcionariam (Portugal $1808 b, c, d$, e).

O mais antigo indício de que as imediações da Real Fábrica de Pólvora poderiam receber plantações determinadas "por ordem superior" encontra-se no Decreto de 12 de outubro de 1808 , que estabelece o cargo de feitor da fazenda da Lagoa de Freitas:

[...] $2^{\circ}$. Será da sua particular incumbência [feitor] conservar no melhor amanho todas as terras que não estão arrendadas [em torno da fábrica], empregando-as naquela espécie de cultura que for de maior interesse e benefício da Real Fazenda, ou em qualquer outra plantação que lhe for determinada por ordem superior (Portugal 1808a).

Uma carta de 18 de novembro de 1808 , em que Rodrigo de Souza Coutinho menciona "o partido que conviria tirar das grandes terras da Lagoa de Freitas, ora incorporadas nos Próprios da Coroa, me ocorreu a tentativa de fazer ensaiar ali a plantação de várias árvores da Ásia" (Coutinho 1808b; Fig. 3), reforça a hipótese de que a ideia ganhara força apenas no segundo semestre daquele ano.

Ainda em novembro, duas cartas de Fernando José de Portugal e Castro anunciam a chegada de sementes remetidas da Inglaterra, "para que sejam usadas na Lagoa de Freitas" (Castro 1808). Outras remessas se seguem no ano seguinte (Castro 1809), além daquela que o português Luiz de Abreu conseguira "roubar" do jardim colonial francês de Pamplemousses, na Ilha de França e entregar, em julho de 1809, ao tenente-general Carlos Antonio Napion, diretor da Fábrica de Pólvora e do jardim anexo a ela (Abreu 1813).

Surgia assim o Jardim Botânico da Lagoa Rodrigo de Freitas, estabelecimento bicentenário que se consolidou como instituição de investigações técnico-científicas, voltada para o conhecimento da flora do Brasil (Bediaga et al. 2008; Peixoto \& Guedes-Bruni 2010; Forzza et al. 2016). Sua implantação refletiu as dificuldades em organizar instituições científicas com atribuições condizentes com a sede do reino português, revelando ações que oscilaram entre o desejável e o possível (Marchant 1961; Bediaga 2007). 

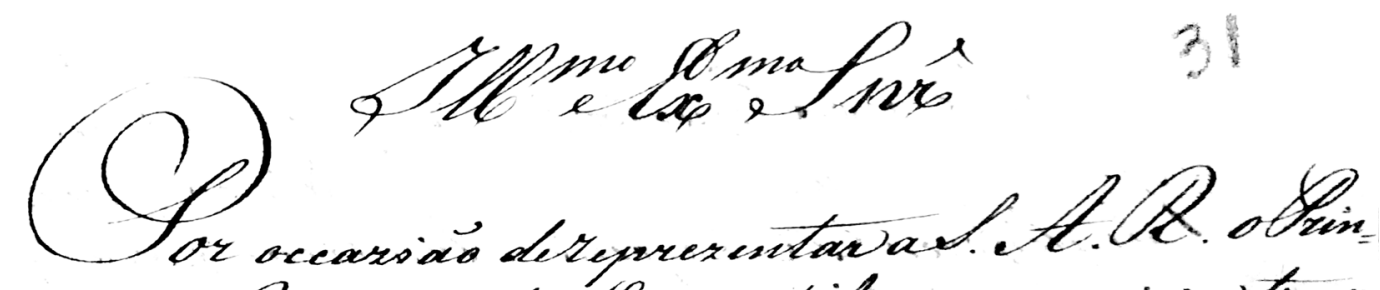
cipe Daequiste. S.e opantide, que conviria tixan

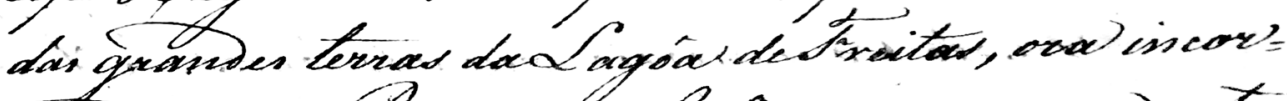

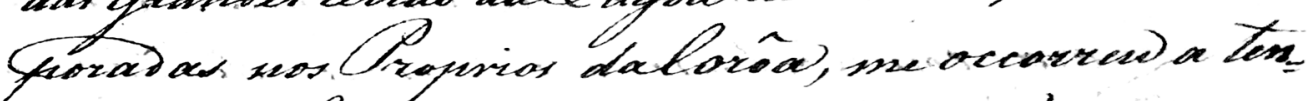

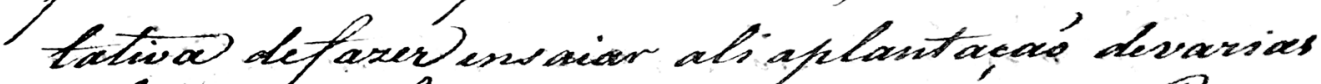

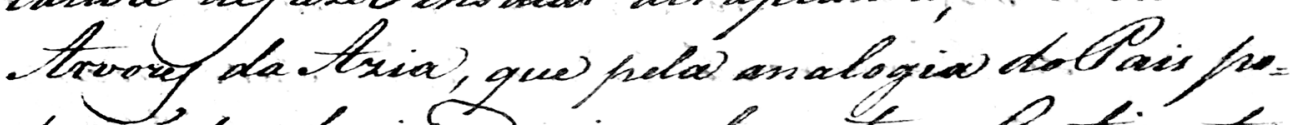

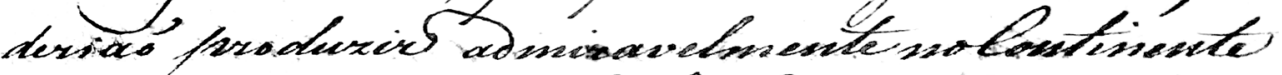

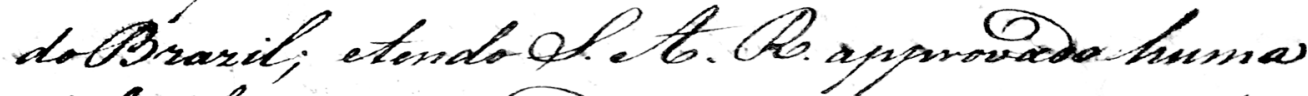

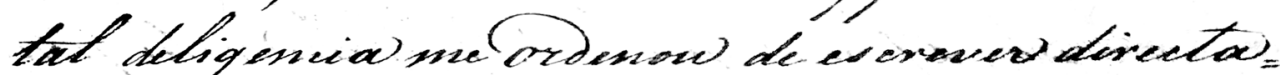

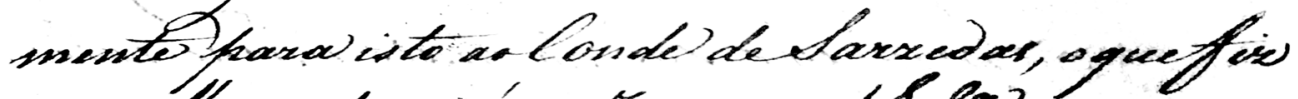

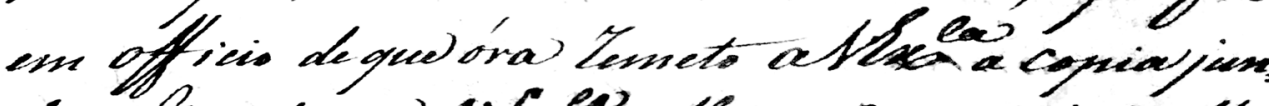

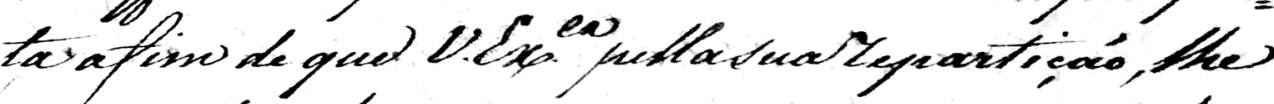

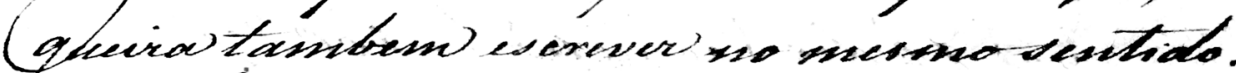

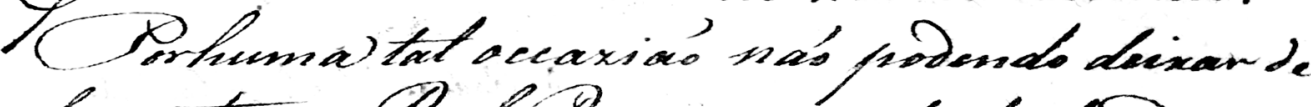

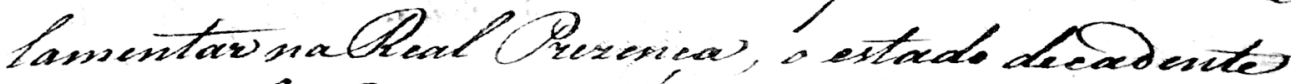

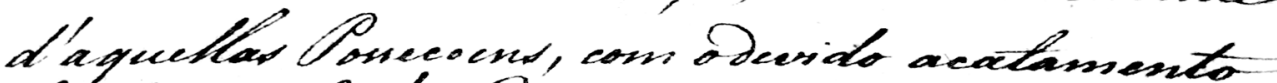

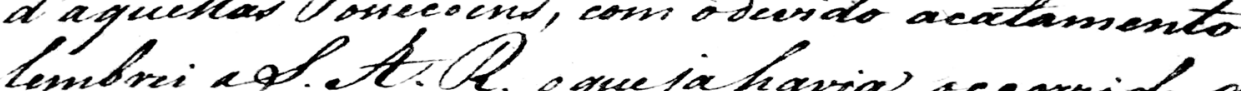

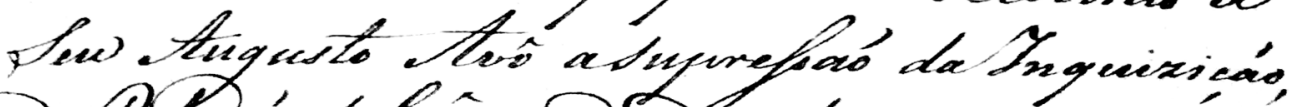

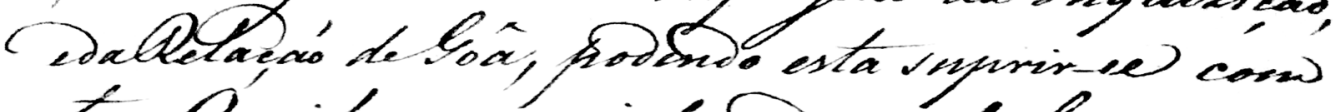

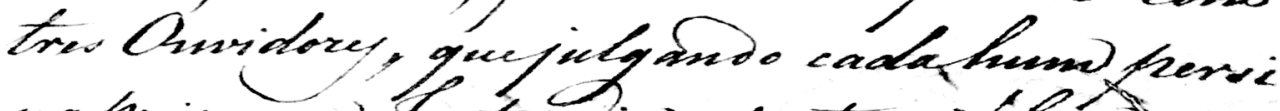
nafisineva Hestanceia

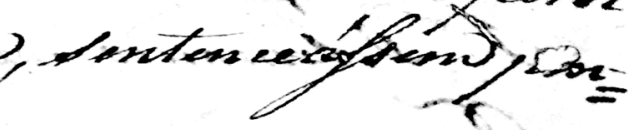

Figura 3 - Trecho da carta de Rodrigo de Souza Coutinho à Fernando José de Portugal, de 1808, em que informa o interesse pelas "terras da Lagoa Rodrigo de Freitas" (Coutinho 1808b).

Figure 3 - Excerpt from the letter of Rodrigo de Souza Coutinho to Fernando José de Portugal, in 1808, in which he informs the interest in the "lands of Rodrigo de Freitas Lagoon" (Coutinho 1808b). 


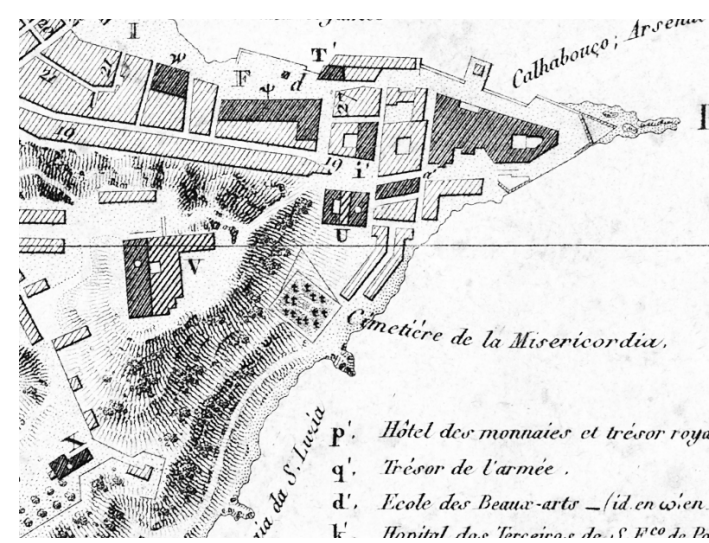

Figura 4 - Detalhe do Plan de la ville de S. Sebastião de Rio de Janeiro produzido pelo explorador francês Louis de Freycinet (1820).

Figure 4 - Detail of Plan de la ville de S. Sebastião de Rio de Janeiro produced by the french explorer Louis de Freycinet (1820).

Quanto ao Horto do Colégio - considerado no presente artigo como primeiro jardim botânico no Rio de Janeiro - o projeto do cirurgião-mór frei Custódio de Campos e Oliveira não teve prosseguimento. Na década de 1820, o terreno foi cedido à irmandade da Santa Casa da Misericórdia, que ali acomodou um cemitério, como explicita o mapa da cidade (Fig. 4). Durante a provedoria do conselheiro José Clemente Pereira (período de 1838 a 1854), o terreno foi apropriado para a edificação do novo hospital da Santa Casa (Moreira de Azevedo 1877, p.358; Abreu 1901, p.249-250; Gandelman 2001).

\section{Referências}

Abreu E (1901) A physicatura mór e o cirurgião mór dos exércitos no Reino de Portugal e Estados do Brazil. Revista Trimestral do Instituto Histórico e Geográfico de Minas Gerais 63 parte I: 154-306.

Abreu L (1813) Botanica. O Patriota (mar.): 16-18.

APG IV (2016) An update of the Angiosperm Phylogeny Group classification for the orders and families of flowering plants. Botanical Journal of the Linnean Society 181: 1-20.

Barrow J (1806) A voyage to Cochinchina, in the years 1792 and 1793. To which is annexed an account of a journey made in the years 1801 and 1802 , to the residence of the chief of the Booshuana nation. T. Cadell and W. Davies, London. 447p.

Bediaga B (2007) Conciliar o útil ao agradável e fazer ciência: Jardim Botânico do Rio de Janeiro - 1808 a 1860. História, Ciências, Saúde - Manguinhos 14: 1131-1157.
Bediaga B, Lima HC, Morim MP \& Barros CF (2008) As atividades científicas durante dois séculos. In: Jardim Botânico do Rio de Janeiro 1808-2008. Instituto de Pesquisas Jardim Botânico do Rio de Janeiro, Rio de Janeiro. Pp. 33-42.

Brigola JCP (2016) O espaço museológico condicionantes do lugar no primeiro museu português (1768). In: Brigola JCP (ed.) Museus, património e ciência: ensaios de história da cultura. Vol. 3. Cidehus, Évora. Pp. 154-161.

Carolino LM (2014) Dom Rodrigo de Sousa Coutinho, a ciência e a construção do império luso-brasileiro: a arqueologia de um programa científico. In: Gesteira H, Carolino LM \& Marinho P (eds.) As formas do Império. Paz e Terra, Rio de Janeiro. Pp. 191-228.

Castro FJP (1808) Cartas (duas) ao conde de Linhares informando sobre sementes de cânhamo e outras plantas remetidas da Inglaterra, para que sejam usadas na Lagoa de Freitas. Arquivo Nacional, Registro de avisos e ofícios da Corte, Livro $1^{\circ}$ da Corte, fundo A6 (Série Interior), caixa IJJ $^{1} 758$. Rio de Janeiro.

Castro FJP (1809) Carta do Conde de Aguiar para o Conde de Linhares, onde informa sobre o envio de sete saquinhos de sementes de diversas plantas, remetidas da Inglaterra, para que sejam usadas como desejar, na Lagoa de Freitas. Arquivo Nacional, fundo A6 (Série Interior), caixa IJJ $^{1}$ 155, f. 237 v.

Castro JL (1795) Carta de José Luís de Castro (vice-rei) a Luiz Pinto de Souza Coutinho (ministro). Arquivo Nacional, fundo 86 (Secretaria de Estado do Brasil), códice 69. Vol. 5. Pp. 260-262.

Castro JL (1799) Carta do conde de Rezende, José Luís de Castro, a d. Rodrigo de Souza Coutinho informando sobre a experiência do cultivo do linho cânhamo. Arquivo Nacional, fundo 86 (Secretaria de Estado do Brasil), caixa 746, pct.01. doc.34, c.833, fls. $34 \mathrm{v} ., 35$ e 36 .

Coutinho RS (1808a) Carta a d. Fernando José de Portugal, solicitando que este escreva à Junta da Fazenda para que não seja feito o arrendamento da chácara do Hospital Real dos Exércitos. Arquivo Nacional, fundo 9S (Série Guerra), IG6 1.

Coutinho RS (1808b) Carta de D. Rodrigo de Souza Coutinho à D. Fernando José de Portugal. Informa que tendo de representar à SAR o partido que convinha tirar das terras da Lagoa Rodrigo de Freitas, resolveu pela tentativa de ensaiar uma plantação de várias árvores da Ásia. Arquivo Nacional, fundo A6 (Série Interior), IJJ $^{1} 758$, fls. 31 e $31 \mathrm{v}$.

Coutinho RS (1801) Carta de d. Rodrigo de Souza Coutinho ao vice-rei do Brasil, conde de Rezende. Arquivo Nacional, fundo 59 (Negócios de Portugal), códice 68 , vol. 17 , f.64.

Coutinho RS (2008 [1798]) Discurso I - feito pelo III.

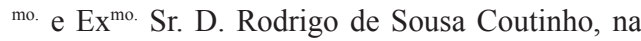
abertura da Sociedade Real Marítima, em 22 de 
dezembro de 1798 In: Chacon V (ed.) O Conde de Linhares / Dom Rodrigo Domingos Antonio de Sousa Coutinho. Thesaurus, Brasília. Pp. 105-115.

Coutinho RS (2008 [1800]) Discurso II - que na Sessão Publica da Sociedade Real Maritima, Militar e Geographica, em a Presença Augusta de S. Alteza Real O Príncipe Regente N. S. Recitou Dom Rodrigo de Sousa Coutinho, Conselheiro d'Estado e Ministro e Secretario d'Estado dos Negócios da Marinha, e Domínios Ultramarinos, na tarde do dia VII de janeiro, de MDCCC. In: Chacon V (ed.) O Conde de Linhares / Dom Rodrigo Domingos Antonio de Sousa Coutinho. Thesaurus, Brasília. Pp. 117-127.

D. João VI (1798) Carta Régia. Arquivo Histórico Ultramarino, códice 574, f.69v-70.

D. João VI (1800) Carta de d. João (príncipe regente) para d. Fernando José de Portugal (vice-rei do Brasil). Arquivo Nacional, fundo 86 (Secretaria do Estado do Brasil), códice 67, vol. 26.

Domingues Â (2001) Para um melhor conhecimento dos domínios coloniais: a constituição de redes de informação no Império português em finais do Setecentos. História, Ciências, Saúde Manguinhos 8(supl.): 823-838.

Ferraz MJS (1795) Manoel Joaquim de Souza Ferraz para d. José Luiz de Castro (vice-rei), de dezembro de 1795. Arquivo Nacional, fundo 86 (Secretaria do Estado do Brasil), códice 69, vol. 5, fls.263-264v.

Ferreira JH \& Paiva MJH (1772-1773) Dissertação sobre a cochonilha. Arquivo Nacional da Torre do Tombo: Manuscritos da Livraria, n. ${ }^{\circ}$ 758. Disponível em $<$ http://digitarq.arquivos.pt/details?id=6041436> Acesso em 24 fevereiro 2017.

Forzza RC, Carvalho Jr A, Andrade ACS, Franco L, Estevão LA, Fonseca-Kruel VS, Coelho MAN, Tamaio N \& Zappi D (2016) Coleções biológicas do Jardim Botânico do Rio de Janeiro à luz das metas da GSPC/CDB: onde estaremos em 2020? Museologia \& Interdiciplinaridade 5: 135-159.

Freycinet LCS (1820) Plan de la ville de S. Sebastião de Rio de Janeiro. Bibliothèque Nationale de France, département Cartes et Plans, GE D-13938

Gandelman LM (2001) A Santa Casa da Misericórdia do Rio de Janeiro nos séculos XVI a XIX. História, Ciências, Saúde - Manguinhos 8: 613-630.

Kury L (2004) Homens de ciência no Brasil: impérios coloniais e circulação de informações (1780-1810). História, Ciências, Saúde Manguinhos 11(supl. 1): 109-129.

Kury L (2007) Descrever a Pátria, Difundir o Saber. In: Kury L (ed.) Iluminismo e Império no Brasil: O Patriota (1813-1814). Editora Fiocruz, Rio de Janeiro. Pp. 141-170.

Marchant A (1961) Dom João’s Botanical Garden. The Hispanic American Historical Review 41: 259-274.
Marques VRB (2005) Escola de homens de ciências: a Academia Científica do Rio de Janeiro, 1772-1779. Educar em Revista 25: 39-57.

Mascarenhas LAPSAEMS (1842 [1789]) Officio de 20 de agosto de 1789 do Vice-Rei Luiz de Vasconcellos e Souza, com a copia da relação instructiva e circumstaciada para ser entregue ao seu successor, na qual mostra o estado em que deixa os negocios mais importantes do seu governo, sendo um d'elles a demarcação de limites da America Meridional. Revista Trimensal de Historia e Geographia, ou Jornal do Instituto Historico Geographico Brasileiro 4: 409-486.

Mello Moraes AJ (1879) Chronica geral e minuciosa do Imperio do Brazil desde a descoberta do Novo Mundo ou America até o anno de 1879. Typographia Carioca, Rio de Janeiro. 208p.

Moreira de Azevedo MD (1877) O Rio de Janeiro: sua historia, monumentos, homens notaveis, usos e curiosidades. Vol. 1. B.L. Garnier, Rio de Janeiro. 470p.

Oliveira CC (1808) Representação do cirurgião-mór dos Exércitos, Custódio de Campos e Oliveira, contra o arrendamento da chácara contígua ao Hospital Militar. Arquivo Nacional, fundo 9S (Série Guerra), IG6 1.

Pádua JA (2002) Um sopro de destruição: pensamento político e crítica ambiental no Brasil escravista, 1786-1888. Jorge Zahar, Rio de Janeiro. 308p.

Paiva MJH (1814) Sumario da história do descobrimento da Cochonilha no Brazil, e das observações, que sobre ella fez o Dr José Henriques Ferreira. O Patriota (jan.-fev.): 3-13.

Papavero N \& Claps L (2014) Alguns dados históricos sobre as cochonilhas do carmim (hemiptera, homoptera, dactylopiidae): notas sobre etimologia, seu cultivo no brasil no século XVIII e na primeira metade do século XIX. Vol. 4. FFLCH/USP, São Paulo. Disponível em <http://www.usp.br/nehilp/ arquivosdonehilp/NEHiLP_4.pdf $>$ Acesso em 13 junho 2017.

Peixoto AL \& Guedes-Bruni RR (2010) No Rio de Janeiro, um jardim botânico bicentenário. Ciência e Cultura 62: 32-35.

Pereira MRM (2014) D. Rodrigo e frei Mariano: a política portuguesa de produção de salitre na virada do século XVIII para o XIX. Topoi 15: 498-526.

Portugal (1808a) Decreto $\mathrm{s} / \mathrm{n}^{\circ}$, de 12 de outubro de 1808 (cria o lugar de Feitor da Fazenda da Lagoa de Freitas e dá instruções a respeito). In: Colecção das leis do Brazil de 1808 [1891]. Editado por Simões JI, Rio de Janeiro. Imprensa Nacional 1: 147-148.

Portugal (1808b) Decreto $\mathrm{s} / \mathrm{n}^{\circ}$, de 13 de junho de 1808 (manda contrair empréstimo para estabelecimento da Fábrica de Pólvora). In: Colecção das leis do Brazil de 1808 [1891]. Editado por Simões JI, Rio de Janeiro. Imprensa Nacional 1: 53-54. 
Portugal (1808c) Decreto s/no de 13 de junho de 1808 (manda incorporar aos próprios da Coroa o engenho e terras da Lagoa Rodrigo de Freitas). In: Colecção das leis do Brazil de 1808 [1891]. Editado por Simões JI, Rio de Janeiro. Imprensa Nacional 1: 52.

Portugal (1808d) Decreto $\mathrm{s} / \mathrm{n}^{\circ}$, de 13 de junho de 1808 (manda tomar posse do engenho e terras da Lagoa Rodrigo de Freitas). In: Colecção das leis do Brazil de 1808 [1891]. Editado por Simões JI, Rio de Janeiro. Imprensa Nacional 1: 53.

Portugal (1808e) Decreto $\mathrm{s} / \mathrm{n}^{\circ}$, de 13 de maio de 1808 (cria uma Fábrica da Pólvora no Rio de Janeiro). In: Colecção das leis do Brazil de 1808 [1891]. Editado por Simões JI, Rio de Janeiro. Imprensa Nacional 1: 30-31.

Quintão JJS (1813) Memória sobre a cochonilha e o methodo de a propagar, offerecida aos lavradores Brazileiros, por hum patriota zelozo, e amante da felicidade publica. O Patriota (out.): 11-19

Sanjad NR (2001) Nos Jardins de São José: uma história do Jardim Botânico do Grão Pará, 17961873. Dissertação de Mestrado. Pós-Graduação em Geociências Área de Educação Aplicada às Geociências, Instituto de Geociências, Unicamp, Campinas. 216p.

Sanjad NR (2006) Éden domesticado a rede lusobrasileira de jardins botânicos, 1790-1820. Anais da História de Além-mar 7: 251-278.

Segawa H (1996) O amor ao público: jardins no Brasil. Estudio Nobel/Fapesp, São Paulo. 255p.

Silva AM (1997) Hospital Central do Exército: 17681998. Revista do Instituto Histórico e Geográfico Brasileiro 158: 977-1017.

Silva MBN (2013) Cultura letrada e cultura oral no Rio de Janeiro dos vice-reis. Editora Unesp, São Paulo. 350p.

Souto PSF (1812) Planta da cidade de São Sebastião do Rio de Janeiro levantada por ordem de sua alteza o Príncipe Regente Nosso Senhor no ano de 1808, feliz e memorável época de sua chegada à dita. Imprensa Regia, Rio de Janeiro.

Staunton GL (1797) An authentic account of an embassy from the King of Great Britain to the Emperor of China. Vol. 1. W. Pulmer \& Co., London. 518p.

Vandelli D (1770) Memória sobre a utilidade dos jardins botânicos a respeito da agricultura e principalmente da cultivação das charnecas. Real Officina da Universidade, Lisboa. 23p.

Vieyra A (1813) A dictionary of the portuguese and english languages. Vol. 2. F. Wingrave, London.

Wehling A (1977) O fomentismo português no final do século XVIII: doutrinas, mecanismos, exemplificações. Revista do Instituto Histórico e Geográfico Brasileiro 316: 170-278. 